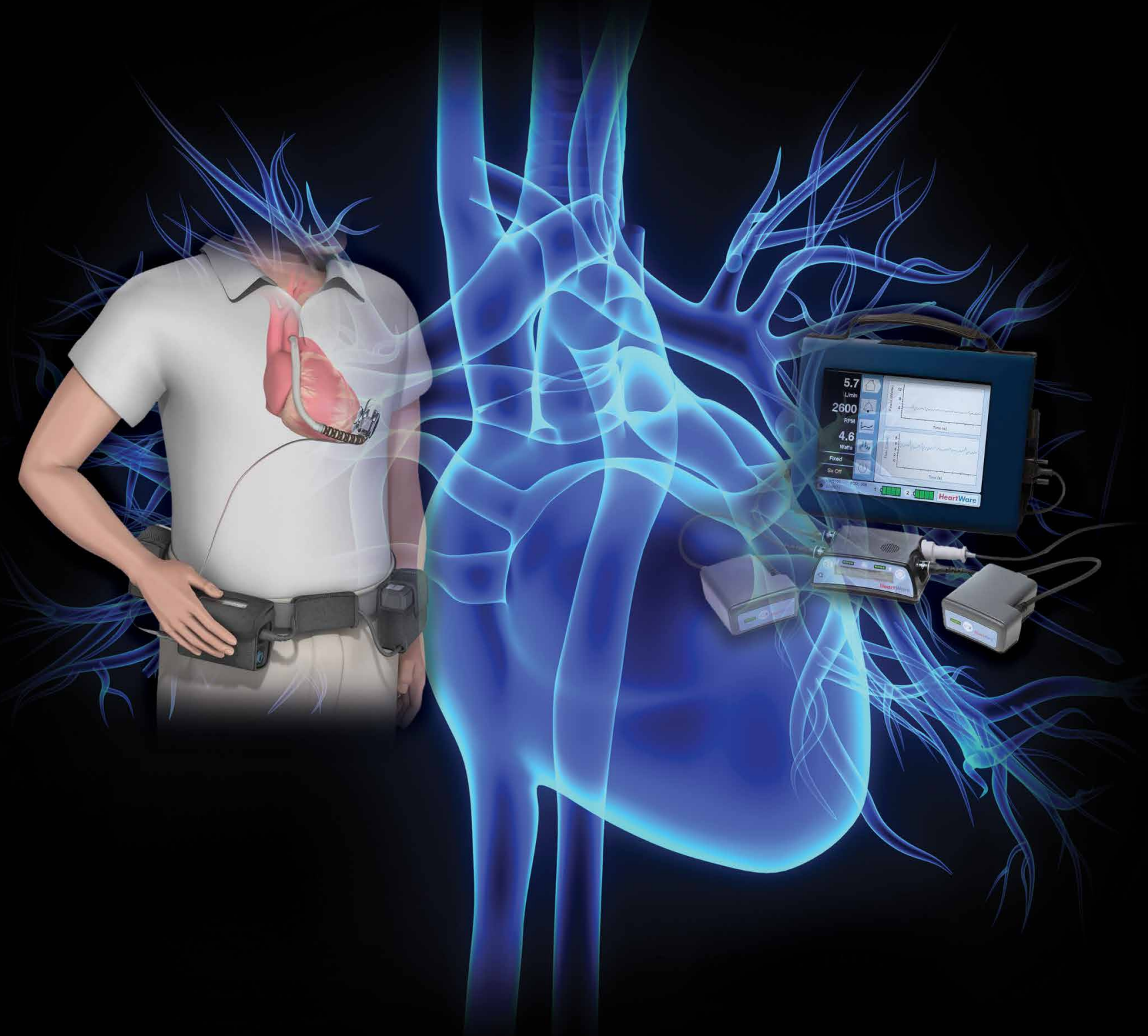




\section{Troubleshooting the Left Ventricular Assist Device}

Alicia S. Devine, JD, MD

\section{In an update and complement to a previously published article, the author provides a review of left ventricular assist device (LVAD) components, with a focus on troubleshooting the device and evaluating LVAD patients in the emergent-care setting.}

\section{Introduction}

Between 2006 and 2013, over 9,000 continuous flow left ventricular assist devices (LVADs) were implanted in patients with end-stage heart failure; nearly 2,500 of these devices were placed in 2013 alone. ${ }^{1}$ As the number of patients with an LVAD continues to grow, so too does the likelihood of a patient with an LVAD presenting to the ED-even if the hospital is not a designated VAD center. An earlier article appearing in the February 2014 issue of Emergency Medicine addressed the management of the unique medical complications faced by patients with LVADs. ${ }^{2}$ This article focuses on troubleshooting the device when a patient with a LVAD presents to the ED.

\section{Device Indications and Types}

Left ventricular assist devices are mechanical implantable devices that provide circulatory support to patients with refractory advanced heart failure. A few of these devices are approved by the US Food and Drug Administration for use as either a bridge to heart transplant or as destination therapy if the patient is not a candidate for heart transplant.
Nearly all of the LVADs currently on the market are designed to provide continuous flow. ${ }^{3-6}$ The most commonly employed LVADs include the HeartMate II (Thoratec Corporation, Pleasanton, California), HeartWare Ventricular Assist System (HeartWare, Framingham, Massachusetts), and the Jarvik 2000 VAS (Jarvik Heart, New York, New York) (Table). These devices differ somewhat in configuration, but the initial management of LVAD patients with a device malfunction is essentially the same.

Even though the type of device is clearly marked on the patient's controller, to ensure appropriate management and facilitate troubleshooting for malfunction, patients should always carry an information card identifying the type of device implanted, as well as the complete contact information for each of their health care providers, including their LVAD coordinator.,

\section{Device Components}

Left ventricular assist devices consist of several different components. All LVADs consist of a pump, controller, driveline, and batteries/battery pack that work together to augment function of the native heart.

Dr Devine is an assistant professor in the department of emergency medicine, Eastern Virginia Medical School; and a member of Emergency Physicians of Tidewater Norfolk.

DOI: 10.12788/emed.2016.0012 


\section{Pump}

The LVAD pump is surgically implanted into the patient's abdominal or chest cavity, with an inflow cannula positioned in the left ventricle and an outflow cannula inserted into the ascending aorta. The pump is designed to have a single internal moving part called the impeller. The pump draws blood from the left ventricle and directs it to the aorta.

\section{Controller and Driveline}

The actions of the pump are directed by a controller, a mini-processor contained in a small box located outside the patient's body. This processor is connected to the pump by a driveline inside the body. The driveline exits the body through the patient's abdominal wall and connects to the controller. The controller regulates the pump speed and provides information about pump speed, flow, pulsatility index, and power of the LVAD.,4

Speed Monitor. The LVAD speed on the controller is usually set at the time of discharge from the hospital; most devices cannot be changed manually.

Power Monitor. On the monitor, the "power" indictor reflects the voltage and current of the pump motor, whereas the "flow" indicator is a reflection of both power and speed (ie, the higher the power, the higher the flow and vice versa).

Batteries/Battery Pack. The LVAD is powered by two batteries attached to the controller or, in some models, to a power base unit that can be plugged into an electrical outlet. Each battery is connected to the controller by a separate connector wire. When battery power in the device becomes low, the batteries should be replaced with fully charged backup batteries, one battery at a time. If the controller is disconnected from both batteries at the same time, the LVAD will lose power and stop working. It is critical to patient health that the LVAD be powered at all times. ${ }^{3,5,7,8}$

Pulsatility Index. Changes in a patient's blood pressure (BP) can affect flow, with higher BP causing a decrease in flow. The pulsatility index reflects the heart's contractility and stretch, as well as the patient's volume status. As the preload decreases (ie, due to a decrease in blood volume) the device will indicate a decreased pulsatility index. If the patient is volume overloaded, the pulsatility index will be increased. Pump speed and pulsatility index are inversely related. In some devices, if the controller detects a significant change in pulsatility index from the prior 15-second average, it will reduce the pump speed to low and then gradually accelerate to the set fixed speed. ${ }^{3,8}$ Significant changes in pulsatility index often indicate an event has occurred, such as an obstruction of the inflow cannula, a decrease in the patient's volume status, an arrhythmia, or increased pulmonary artery pressure suggestive of right heart failure., ${ }^{3,4}$

\section{Patient Responsibility}

Following LVAD placement, patients are discharged from the hospital with extra batteries (usually four to six), a batterycharger station, a spare controller, and in certain models, a power base unit that can power the LVAD when they are at home and/or asleep. When patients are away from home, they should always have extra fully charged batteries, the spare controller, information about their device, and the complete names and contact information for their health care providers (ie, cardiologist, cardiothoracic surgeon, VAD coordinator) with them at all times. ${ }^{3,7,8}$

\section{Patient Evaluation and}

\section{Troubleshooting the Device}

When a patient with an LVAD presents to the ED, regardless of reason or chief complaint, the emergency physician (EP) should begin assessing the patient while the unit secretary pages the patient's LVAD coordinator and the hospital perfusionist. If the EP's hospital does not routinely care for LVAD patients, an excellent resource is www.mylvad.com, which pro- 
Table. Comparison of Common Ventricular Assist Devices

\begin{tabular}{|c|c|c|c|c|}
\hline $\begin{array}{l}\text { Device Component/ } \\
\text { Feature }\end{array}$ & HeartMate II & HeartWare & $\begin{array}{c}\text { Jarvik } \\
2000 \text { VAS }\end{array}$ & $\begin{array}{l}\text { Thoratec PVAD } \\
\text { With TLC II Driver }\end{array}$ \\
\hline Flow & Continuous & Continuous & Continuous & Pulsatile \\
\hline Battery life & 8-10 hours & 4-6 hours & $7-12$ hours & 2 hours \\
\hline $\begin{array}{l}\text { Power-off or power- } \\
\text { disconnected indicator }\end{array}$ & $\begin{array}{l}\text { Pocket controller: } \\
\text { audible alarm; green } \\
\text { "pump-running" symbol } \\
\text { will not be lit; "connect } \\
\text { power" message } \\
\text { will display } \\
\text { External peripheral } \\
\text { controller: steady, } \\
\text { audible alarm; green } \\
\text { power light will not be lit }\end{array}$ & $\begin{array}{c}\text { Audible alarm; flashing red } \\
\text { alarm light, and "VAD stopped" } \\
\text { message will display } \\
\text { Action message will display } \\
\text { "connect driveline," "change } \\
\text { controller," or "replace battery" }\end{array}$ & $\begin{array}{l}\text { Audible alarm; red } \\
\text { "pump stopped" } \\
\text { symbol will be lit }\end{array}$ & $\begin{array}{l}\text { "Empty" signal light } \\
\text { will flicker }\end{array}$ \\
\hline Low-battery indicator & $\begin{array}{l}\text { Pocket controller: } \\
\text { yellow or red battery light } \\
\text { will be lit; "low battery" } \\
\text { and "replace power" } \\
\text { messages will display } \\
\text { External peripheral } \\
\text { controller: } \\
\text { yellow or red battery light } \\
\text { will be lit }\end{array}$ & $\begin{array}{c}\text { Audible alarm; solid yellow } \\
\text { "triangle" light lit and } \\
\text { "low battery" message } \\
\text { will display }\end{array}$ & $\begin{array}{l}\text { Beeping alarm; low- } \\
\text { battery light is yellow }\end{array}$ & $\begin{array}{l}\text { Audible alarm; red } \\
\text { light will be lit }\end{array}$ \\
\hline Low-flow indicator & $\begin{array}{l}\text { Pocket controller: } \\
\text { "audible alarm; red } \\
\text { "heart" flashing light, } \\
\text { "low flow," and "call } \\
\text { hospital contact" } \\
\text { messages will display } \\
\text { External peripheral } \\
\text { controller: } \\
\text { audible alarm; } \\
\text { red "heart" flashing light }\end{array}$ & $\begin{array}{l}\text { Flashing yellow light and "low- } \\
\text { flow" message will display }\end{array}$ & None & "Loss of flow" alarm \\
\hline $\begin{array}{l}\text { Driveline disconnected } \\
\text { indicator }\end{array}$ & $\begin{array}{l}\text { Pocket controller: } \\
\text { audible alarm; red } \\
\text { "heart" flashing light, } \\
\text { green "pump running" } \\
\text { symbol will not be lit, } \\
\text { and "connect driveline" } \\
\text { message will display } \\
\text { External peripheral } \\
\text { controller: } \\
\text { audible alarm; } \\
\text { red "heart" flashing light }\end{array}$ & $\begin{array}{l}\text { Audible alarm; flashing red } \\
\text { alarm light and "VAD stopped" } \\
\text { message will display } \\
\text { Action message will display } \\
\text { "connect driveline" }\end{array}$ & $\begin{array}{l}\text { Audible alarm; red } \\
\text { "pump stopped" } \\
\text { symbol will be lit }\end{array}$ & $\begin{array}{l}\text { Audible alarm; red } \\
\text { alarm light will be lit }\end{array}$ \\
\hline
\end{tabular}

\section{Considerations for Use}

\begin{tabular}{|c|c|c|c|c|}
\hline Defibrillation & Yes & Yes & Yes & Yes \\
\hline Cardioversion & Yes & Yes & Yes & No \\
\hline Pacing & Yes & Yes & Yes & $\begin{array}{l}\text { Use in "Bi-VAD" } \\
\text { configuration }\end{array}$ \\
\hline $\begin{array}{l}\text { Cardiopulmonary } \\
\text { Resuscitation }\end{array}$ & $\begin{array}{l}\text { With caution and } \\
\text { as a last resort }\end{array}$ & With caution and as a last resort & $\begin{array}{l}\text { With caution and as a } \\
\text { last resort }\end{array}$ & No \\
\hline Hand pump & No & No & No & Yes \\
\hline \multirow[t]{2}{*}{$\begin{array}{l}\text { Mean arterial pressure } \\
\text { parameters }\end{array}$} & $\begin{array}{l}70-85 \mathrm{~mm} \mathrm{Hg} \\
\text { (nonpulsatile) }\end{array}$ & $\begin{array}{l}\text { 70-80 mm Hg } \\
\text { (nonpulsatile) }\end{array}$ & $65-80 \mathrm{~mm} \mathrm{Hg}$ & $\begin{array}{l}\text { Normal blood } \\
\text { pressure }\end{array}$ \\
\hline & $\begin{array}{c}90-110 \mathrm{~mm} \mathrm{Hg} \\
\quad \text { (pulsatile) }\end{array}$ & $\begin{array}{l}\text { 85-105 mm Hg } \\
\text { (pulsatile) }\end{array}$ & & \\
\hline Pulse present & Weak or absent & Weak or absent & $\begin{array}{l}\text { Most have a faint } \\
\text { palpable pulse }\end{array}$ & Yes \\
\hline Electrocardiogram & Not affected & Not affected & Not affected & $\begin{array}{l}\text { Does not correlate } \\
\text { with patient's pulse }\end{array}$ \\
\hline
\end{tabular}

Source: Mechanical Circulatory Support Organization EMS Field Guide, January 2015, Heartware System Alarm Troubleshooting Clinician Guide, HeartMate Il Left Ventricular Assist System Alarms for Clinicians. 
vides links to emergency medical service field guides for management of patients with all types of LVADs. The field guides provide step-by-step instructions for troubleshooting each type of LVAD, including instructions for replacing batteries and controllers. $^{7,8}$

\section{Perfusion and Mean Arterial Pressure}

At presentation, the EP should evaluate the patient for signs of poor perfusion (eg, decreased mental status, pallor, cool skin) and, when indicated, provide a fluid bolus. Patients with an LVAD typically do not have palpable pulses due to the continuous flow of their devices. ${ }^{3-7}$ Therefore, a mean arterial pressure (MAP) using a Doppler and a manual BP cuff should be taken. The pressure at which the first sound is heard is used as the estimate of the MAP. The MAP for an LVAD patient generally should be between 70 and $90 \mathrm{~mm} \mathrm{Hg.,3,7}$

Patients with an LVAD are afterload sensitive, and high BP must be addressed immediately to avoid morbidity. Elevated $\mathrm{BP}$ increases the work of the pump against increased peripheral resistance, which can lead to thrombus and stroke. ${ }^{7}$

\section{Power and Connections}

The EP should always check the controller to make sure the power light is on. Once this has been confirmed, she or he should auscultate over the patient's chest and abdomen to detect the humming sound of the pump. If the pump is not powered or does not appear to be functioning, the controller

\section{LVAD Parameter Abnormalities}

- High power, low-pulsatility index and fluctuating pump speed: Consider pump thrombosis or hypotension.

- High power with high pulsatility index: Consider fluid overload.

- Low power, low pulsatility index, and unchanging speed: Consider hypertension or inflow/outflow obstruction.

- Low power with normal or high pulsatility index: Consider suction event should be replaced with the patient's backup controller. Next, all connections to the power source and the connection between the driveline and the controller should be checked to confirm they are intact. After this has been completed, the connections should be disconnected and reconnected. Then the driveline should be evaluated for defects or damage.

\section{Battery Assessment}

While troubleshooting the LVAD for malfunction, the batteries on the device should be replaced with backup batteries or connected to the hospital's power base unit (if one exists) or to the patient's power base unit if it is present. If a battery replacement is required, before doing so, the patient should first be positioned flat on the stretcher or bed. ${ }^{7}$

\section{Low-Flow Indicator}

The EP should always check the controller to determine which alarms, if any, are flashing. Although the alarm buttons vary among the various LVAD devices, all types have a "low-flow" indicator. If the controller indicates low flow, the patient first should be given a fluid bolus. Patients with LVADs are preload dependent, and given their history of heart failure and fluid restriction, are often reluctant to maintain good fluid intake once an LVAD has been implanted..$^{3,7}$

Another important etiology for a lowflow reading on the LVAD controller is pump thrombosis. Pump thrombosis should be considered when the MAP is low and the controller indicates a decreased pulsatility index and decreased flow. Often the RPMs (the speed) are increased as the controller attempts to adjust to the thrombosis with an increase in power. A bedside echocardiogram showing dilated right and left ventricles is consistent with a pump thrombosis. Treatment for pump thrombosis is anticoagulation with heparin or thrombolytics, and cardiothoracic surgery should be consulted. ${ }^{3}$ 


\section{Suction Events}

In addition to hypovolemia, another cause of hypotension is a "suction event" in which the left ventricle is not filling but the pump continues to attempt to pull blood from it and the walls of the ventricle suck in on themselves. Suction events can also be caused by cannula malposition, increased peripheral vascular resistance, and tamponade. A small left ventricle on bedside echocardiogram is consistent with a suction event. Often, the controller can sense this and will respond by slowing the pump speed and slowly bringing it back up to allow the ventricles to reaccumulate blood. Initial treatment consists of a fluid bolus and cardiothoracic surgery consultation..$^{3,4}$

\section{Low Battery}

If an LVAD patient presents to the ED with a low battery, no backup batteries, and the hospital does not have a power base unit or other way to power the LVAD, the EP should call the patient's VAD coordinator to assist. Often, the coordinator can identify a local LVAD patient who is willing to transport extra batteries to the ED.

To conserve power, the controller in some LVAD models is

programmed to automatically reduce the pump speed when the battery power becomes low. This feature can be a cause of syncope or lightheadedness in in some patients. While some older LVAD models had the capability of being powered by a hand pump in the event of loss of function, the newer devices do not. ${ }^{4,7,8}$

\section{Cardiac Assessment and Protocols}

The presence of an LVAD should not have any effect on electrocardiography studies. When evaluating patients, standard advanced cardiac life support protocols should be followed, but extreme caution should be used before starting chest compressions as this can dislodge the cannula and lead to death. Prior to initiating chest compressions, the patient's VAD coordinator should be contacted to ensure that any problems with the device itself have been considered, addressed, and ruled out. Defibrillation, cardioversion, and pacing are all acceptable in LVAD patients, but defibrillator or pacer pads should not be placed directly over the patient's pump. ${ }^{7}$

\section{Summary}

As the number of patients with an implantable cardiac device continues to grow, EPs are likely to encounter an LVAD patient in the ED. An understanding of device function and knowledge of the basic troubleshooting skills can prove life-saving in many instances. In addition, a familiarity with available LVAD resources, both online and within the health care community, is also essential to ensure the appropriate management and care of these patients.

\section{References}

1. Kirklin JK, Naftel DC, Pagani FD, et al. Sixth INTERMACS annual report: a 10,000-patient database. J Heart Lung Transplant. 2014; 33(6):555-564.

2. Devine AS. Left ventricular assist devices: from mystery to mastery. Hardware for the heart: the increasing impact of pacemakers, ICDs, and LVADs. Emerg Med. 2014;46(2):72-75.

3. Slaughter MS, Pagani FD, Rogers JG, et al; HeartMate II Clinical Investigators. Clinical management of continuous-flow left ventricular assist devices in advanced heart failure. J Heart Lung Transplant. 2010;29(4 Suppl):S1-S39.

4. Klein T, Jacob MS. Management of implantable assisted circulation devices: emergency issues. Cardiol Clin. 2012;30(4):673-682.

5. Felix SE, Martinia Jr, Kirkels JH, et al. Continuousflow left ventricular assist device support in patients with advanced heart failure: points of interest for the daily management. Eur J Heart Fail. 2012;14(4):351356

6. Slaughter MS, Rogers JG, Milano CA, et al; HeartMate II Investigators. Advanced heart failure treated with continuous-flow left ventricular assist device. N Engl J Med. 2009;361(23):2241-2251.

7. Mechanical Circulatory Support Organization. EMS Guide, January 2015. http://mylvad.com/sites/mylvadrp/files/EMS\%20Field\%20Guides/MCSO $\% 20$ EMS\%20GUIDE\% 202015\%20.pdf. Accessed February 2, 2016.

8. Mylvad.com Web site. Accessed February 2, 2016. 